\title{
Postmenopausal endometrial cancer risk and body size in early life and middle age: prospective cohort study
}

\author{
TYO Yang', , BJ Cairns', N Allen', S Sweetland', GK Reeves' and V Beral' on behalf of the Million Women Study \\ 'Cancer Epidemiology Unit, University of Oxford, Richard Doll Building, Roosevelt Drive, Old Road Campus, Oxford OX3 7LF, UK
}

\begin{abstract}
BACKGROUND: Greater adiposity in early life has been linked to increased endometrial cancer risk in later life, but the extent to which this association is mediated through adiposity in later life is unclear.

METHODS: Among postmenopausal women who had never used menopausal hormone therapies and reported not having had a hysterectomy, adjusted relative risks (RRs) of endometrial cancer were estimated using Cox regression.

RESULTS: Among 24979 I postmenopausal women with 7.3 years of follow-up on average ( I.8 million person-years), endometrial cancer risk ( $n=1410$ cases) was strongly associated with current body mass index (BMI) at baseline $\left(R R=1.87 \mathrm{per}^{2} \mathrm{~kg} \mathrm{~m}{ }^{-2}\right.$ increase in BMI, 95\% confidence interval (Cl): I.77-1.96). Compared with women thinner than average at age I0, the increased risk among women plumper at age $10(R R=1.27,95 \% \mathrm{Cl}$ : 1.09-1.49) disappeared after adjustment for current $\mathrm{BMI}(\mathrm{RR}=0.90$, 95\% Cl: 0.77-1.06). Similarly, compared with women with clothes size 12 or less at age 20, the increased risk among women with clothes size 16 or larger $(R R=1.87,95 \% \mathrm{Cl}$ : $1.6 \mathrm{I}-2.18)$ was not significant after adjustment for current $\mathrm{BMI}(\mathrm{RR}=1.03$, 95\% Cl: 0.88-1.22).

CONCLUSION: Among women who have never used hormone therapy for menopause, the association between body size in early life and endometrial cancer risk in postmenopausal women can be largely explained by women's current BMI.

British Journal of Cancer (2012) 107, 169-175. doi: I0.1038/bjc.2012.229 www.bjcancer.com
\end{abstract}

Published online 29 May 2012

(c) 2012 Cancer Research UK

Keywords: endometrial cancer; body mass index; obesity; childhood obesity

Excess body fatness is a major modifiable risk factor for endometrial cancer (Reeves et al, 2007; Renehan et al, 2008; Crosbie et al, 2010), most likely because adipose tissues are an important source of endogenous oestrogens (Calle and Kaaks, 2004; Allen et al, 2008). Studies of breast cancer have shown an independent association of breast cancer risk with body size in early life (Le Marchand et al, 1988; Baer et al, 2010), raising the question of whether there might be a similar association for risk of endometrial cancer. Case-control and cohort studies have suggested an association between large body size in early adulthood and subsequent risk of endometrial cancer (Blitzer et al, 1976; Le Marchand et al, 1991; Olson et al, 1995; Schouten et al, 2004; Trentham-Dietz et al, 2006; Xu et al, 2006; Park et al, 2009; Thomas et al, 2009), but there is limited evidence as to whether this association is mediated or modified by body mass index (BMI) at older ages (Chang et al, 2007; Trentham-Dietz et al, 2006). In postmenopausal women, their current BMI in middle age is strongly associated with larger body size in early life as well as with the risk of endometrial cancer. Greater body size in early life might therefore be linked to increased risk of endometrial cancer largely through its association with a higher BMI in middle age.

In the present study, we investigated the independent associations of endometrial cancer risk with body size at age 10 and 20 years, and in middle age, in a prospective cohort of UK postmenopausal.

*Correspondence: Dr TYO Yang; E-mail: owen.yang@ceu.ox.ac.uk Received 27 January 2012; revised 17 April 2012; accepted 25 April 2012; published online 29 May 2012

\section{MATERIALS AND METHODS}

The Million Women Study (Million Women Study Collaborators, 2003; Allen et al, 2009) is a population-based prospective cohort of 1.3 million middle-aged UK women who completed a recruitment questionnaire when they were invited to routine breast cancer screening between 1996 and 2001. Participants were invited to complete a second survey questionnaire $\sim 3$ years after recruitment to provide additional information, including their body size in early life and clothes sizes at different ages. Full study questionnaires can be found on the Million Women Study website (www.millionwomenstudy.org). All women gave informed consent to participate in the study. Ethical approval for the Million Women Study was granted by the Oxford and Anglia Multi-Centre Research Ethics Committee.

All participants were flagged on the UK National Health Service Central Registers, which routinely provides the investigators with information on deaths and incident cancers, with the cause of death and cancer site coded according to the International Classification of Diseases, 10th Revision (ICD-10).

This analysis is restricted to women who provided information on their body sizes in early life and in middle age. Women were excluded if they reported having had a hysterectomy or if their hysterectomy status was unknown. As use of hormone therapies for the menopause is known to attenuate the association between BMI and endometrial cancer risk (Calle and Kaaks, 2004; Crosbie et al, 2010), all analyses were further restricted to women who were postmenopausal and who had never used hormone replacement therapy. 


\section{Measures of body size variables and their validation}

Body sizes at age 10 years and age 20 years were reported in response to the questions, 'When you were about 10 years old, compared with average, would you describe yourself as: thinner? Plumper? About average?' and, 'What size clothes did you wear when you were about 20 years old?' with options to respond with one or more of: 8 or less, $10,12,14,16$, or $18+$. The clothes size at age 20 years was recorded as the largest value of all indicated sizes (coded as $8,10,12,14,16$, or 18). Current BMI, reported at the baseline of this study (age 60.5 years on average), was calculated by reported current weight (in stones and pounds, converted to $\mathrm{kg}$ ) at the second survey divided by the square of the reported current height (in feet and inches, converted to centimetres) reported at recruitment.

The validity of early life body size variables has previously been investigated (Cairns et al, 2011) in a group of 541 women in the Million Women Study who were also participants in the National Survey of Health and Development (NSHD), a nationallyrepresentative birth cohort, born in a single week in 1946. In the NSHD, BMI was measured at age 11 years and by reported height and weight at ages 20 and 53 years. Women who participated in both cohorts were similar in terms of anthropometry and reproductive history to other Million Women Study participants born within a year of the NSHD cohort, though they tended to have a slightly higher socioeconomic status. Categories of both early-life body size variables from the Million Women Study had moderate to strong associations with BMI recorded by the NSHD at the relevant ages. Spearman's correlations between the reports in middle age in the Million Women Study and at the appropriate age in the NSHD were 0.51 for body size at age 10 years compared with measured BMI at age 11, and 0.63 for body size at age 20 years compared with BMI reported at age 20. Current BMI reported at recruitment to the Million Women Study was also strongly correlated with that measured at age 53 in the NHSD (Pearson's correlation $=0.92)$. Body mass index was also measured in 2006-2009 in a sample of $\sim 3700$ participants in the Million Women Study (Armstrong et al, 2011). Among 2772 postmenopausal women in this validation sample, measurements of BMI were also strongly correlated with that reported at recruitment (Pearson's correlation $=0.85$ ). In order to correct for measurement error, we took the mean BMI within each category of body size to be the mean BMI recorded by the NSHD (for BMI at ages 10 and 20 years) or measured in 2006-2009 (for current BMI).

\section{Statistical analysis}

Eligible women contributed person-years from the date of the second survey (when they provided information on body size in early life), until the date of any cancer registration (except nonmelanoma skin cancer), the date of death, emigration, or other loss to follow-up, or to the last date of follow-up, whichever was earliest. The last dates of follow-up were, by region of recruitment: 31 December 2009 for Oxford, East Anglia, South West, Thames, West Midlands, North Yorks, Trent, and North West (Manchester and Lancashire); 31 December 2008 for North West (Mersey) and Scotland.

In all analyses, the endpoint of interest was endometrial cancer (ICD-10 code C54). Hazard ratios (referred to hereafter as relative risks (RRs)) and 95\% confidence intervals (CIs) were estimated using Cox proportional hazards regression with attained age as the underlying time variable, according to relative body size at age 10 years (thinner, average, and plumper), clothes size at age 20 years (12 or less, 14,16 , or larger), and current BMI $(<22.5,22.5-27.4$, $27.5-32.4,32.5-34.9, \geqslant 35.0 \mathrm{~kg} \mathrm{~m}^{-2}$ ). The RR per $5 \mathrm{~kg} \mathrm{~m}^{-2}$ increase in BMI at each age was calculated across the category mean BMIs obtained from the previously published validation study (Cairns et al, 2011) (for ages 10 and 20 years) or as measured in 2006-2009 (Armstrong et al, 2011) (for current BMI). All analyses were stratified by year of birth (before 1940, 1940-1945, 1946 , or later), region of residence at baseline (Scotland and nine regions in England) and socioeconomic status (quintiles of Townsend deprivation index) (Townsend et al, 1988), that is, baseline hazards were allowed to vary with these characteristics. In some analyses, RRs were additionally adjusted for reproductive and lifestyle factors: age at menarche $(\leqslant 11,12,13,14, \geqslant 15)$, parity (nulliparity, $1, \geqslant 2$ children), age at menopause $(\leqslant 46$, $47-49,50,51-53, \geqslant 54$ years old), history of use of hormonal contraceptives (yes/no), adult height $(<155,155-159,160-164$, $165-169,170-174, \geqslant 175 \mathrm{~cm})$, alcohol consumption $(0,1-4,5-14$, $15-29,30+$ g per day) (Allen et al, 2009), smoking history (never, former smoker who stopped $<10$ or $\geqslant 10$ years, currently smoking $1-14,15-29$, or $30+$ cigarettes per day), and strenuous exercise $(0$, $0.5-1,1.5-3,>3 \mathrm{~h}$ per week). Missing or non-applicable values were treated as a separate category. For analyses of body size at ages 10 or 20 years, further adjustment for BMI (in five categories, as above) was explored to assess possible mediation of the effects of early life body size via body size in middle age. Potential interactions between early-life body size and current BMI at baseline in the risk of postmenopausal endometrial cancer were also assessed by cross-classifying women according to body size in early life and current BMI in three categories $(<25.0,25.0-29.9$, $\geqslant 30.0 \mathrm{~kg} \mathrm{~m}^{-2}$ ).

Where trends are estimated or when two categories are compared (as in the text), conventional 95\% CIs are given, but where results for more than two categories are presented (as in figures and tables), floated 95\% CIs (FCIs) are given, estimated by Plummer's minimum-divergence method (Plummer, 2004). Use of FCIs allows comparisons to be made between any two exposure groups, even if neither is the reference group (Easton et al, 1991). When presented graphically, squares representing RRs have areas that are inversely proportional to the variance of the logarithm of the RR; this indicates the amount of statistical information involved in each estimate. In subgroup analyses, heterogeneity was tested by a $\chi^{2}$-contrast test, and $P$-values for heterogeneity were interpreted after adjustment for multiple testing (Holm, 1979).

All statistical tests were two-sided and were conducted using the Stata computer programme, version 11.1 (StataCorp., College Station, TX, USA).

\section{RESULTS}

Among 249791 women with 1.8 million person-years of follow-up (mean 7.3 years per woman), there were 1410 incident cases of endometrial cancer. The three body size indicators were positively correlated. The Pearson's correlation coefficient was 0.36 between body sizes at age 10 and 20 years, 0.14 between body size at age 10 years and BMI reported at study baseline (referred to as current BMI hereafter), and 0.31 between body size at age 20 years and current BMI. Table 1 shows age-adjusted characteristics of women according to relative body size at age 10 years, clothes size at age 20 years and current BMI. Most age-adjusted reproductive factors and lifestyle factors varied significantly with body size at each age, but the patterns of variation were not consistent across the body size variables. Women who said that they were plumper than average at age 10 years, compared with those who had average or thinner body size, reported an earlier age at menarche and shorter attained adult height. They were more likely to be current smokers and to be nulliparous at study baseline, and slightly less likely to have ever used oral contraceptives. Women who reported average body size at age 10 years, compared with those who were plumper or thinner, were less likely to be in the most deprived group, and more likely to engage in regular strenuous physical activity. The associations of clothes size at age 20 years with these characteristics were similar, except that women reporting larger clothes 


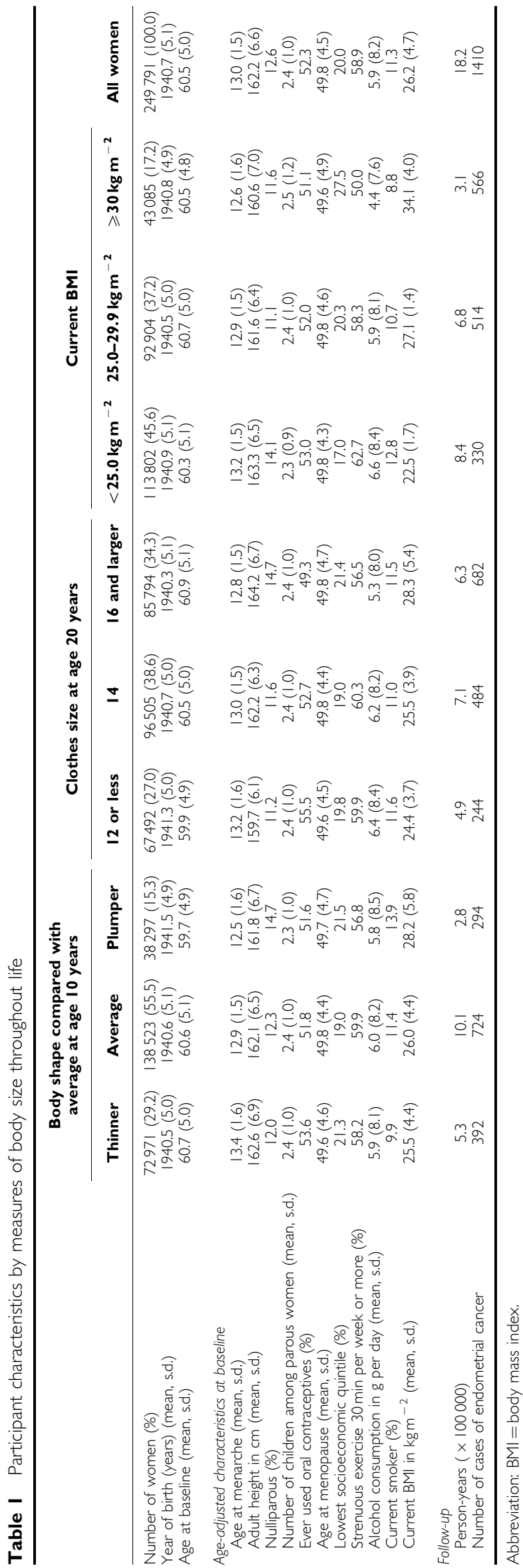

size tended to be taller and consumed less alcohol, and there was no longer a positive association with likelihood of being a current smoker. Associations of current BMI with these characteristics differed further. Women reporting $\mathrm{BMI} \geqslant 30 \mathrm{~kg} \mathrm{~m}^{-2}$ tended to have more children on average and were more likely to be in the most deprived socioeconomic group. They were also less likely to engage in regular strenuous physical activity, consumed less alcohol, and were less likely to be current smokers.

Consistent with a previous report from this cohort (Reeves et al, 2007), current BMI was associated with higher risk of postmenopausal endometrial cancer after adjustment for demographic, reproductive, and lifestyle variables (Figure 1). Risk of endometrial cancer increased strongly with increasing current BMI across the range of values observed in women in this study (RR per $5 \mathrm{~kg} \mathrm{~m}^{-2}$ $=1.87,95 \%$ CI: $1.77-1.96$ ).

Relative body size at age 10 was associated with postmenopausal endometrial cancer after minimal adjustment by stratification for year of birth, region, and socioeconomic status (Table 2). Compared with women who reported being thinner than average at age 10, women who reported having an average body size had a similar risk of endometrial cancer $(\mathrm{RR}=0.98,95 \% \mathrm{CI}: 0.86-1.10)$, whereas women who reported being plumper than average had significantly higher risk ( $R R=1.45,95 \%$ CI 1.25-1.69). This higher risk among women plumper at age 10 years was moderately attenuated after additional multivariable adjustment for reproductive and lifestyle variables other than current $B M I(R R=1.27,95 \%$ CI: 1.09-1.49), and disappeared after further adjustment for current BMI $(\mathrm{RR}=0.90,95 \% \mathrm{CI}: 0.77-1.06)$. These results were consistent with a RR of 1.61 per $5 \mathrm{~kg} \mathrm{~m}^{-2}$ increase in BMI at age 10 years (95\% CI: 1.34-1.94) with minimal adjustment, which was attenuated after additional multivariate adjustment $(\mathrm{RR}=1.40$ per $5 \mathrm{~kg} \mathrm{~m}^{-2}$, 95\% CI: 1.16-1.68), and disappeared after further adjustment for current BMI $\left(\mathrm{RR}=0.91\right.$ per $5 \mathrm{~kg} \mathrm{~m}^{-2}, 95 \% \mathrm{CI}$ : 0.75-1.10).

Larger clothes size at age 20 was also associated with postmenopausal endometrial cancer after minimal adjustment (Table 2). Compared with women who reported having clothes size 12 or less at age 20 , the risk of postmenopausal endometrial cancer was significantly higher among women who reported having clothes size 14 ( $R R=1.37,95 \% \mathrm{CI}: 1.17-1.59)$, and even higher among women with clothes size 16 or larger $(\mathrm{RR}=2.14,95 \% \mathrm{CI}$ : 1.85-2.48). Again, these RRs were attenuated after multivariate adjustment (compared with women with clothes size 12 or less, $\mathrm{RR}=1.31$, 95\% CI: $1.12-1.53$, for size 14 , and $\mathrm{RR}=1.87,95 \% \mathrm{CI}$ : 1.61-2.18, for size 16 or larger), and after further adjustment for

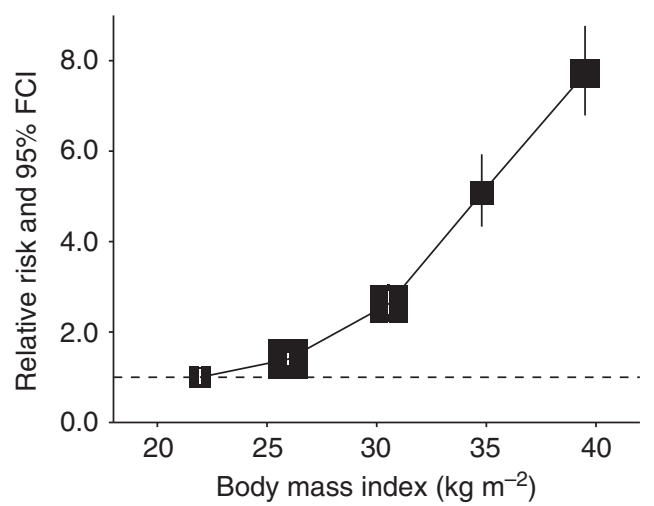

Figure I Relative risks and 95\% floated confidence intervals ( $\mathrm{FCls}$ ) of endometrial cancer by body mass index. Relative risks are adjusted for age, region, socioeconomic status, adult height, age at menarche, parity, age at menopause, use of hormone contraceptives, alcohol consumption, smoking, and strenuous physical activity, and are plotted against the mean measured $\mathrm{BMI}$ in each category. 
Table 2 Adjusted hazard ratios of endometrial cancer according to body size at age 10 or 20 years, and current BMI

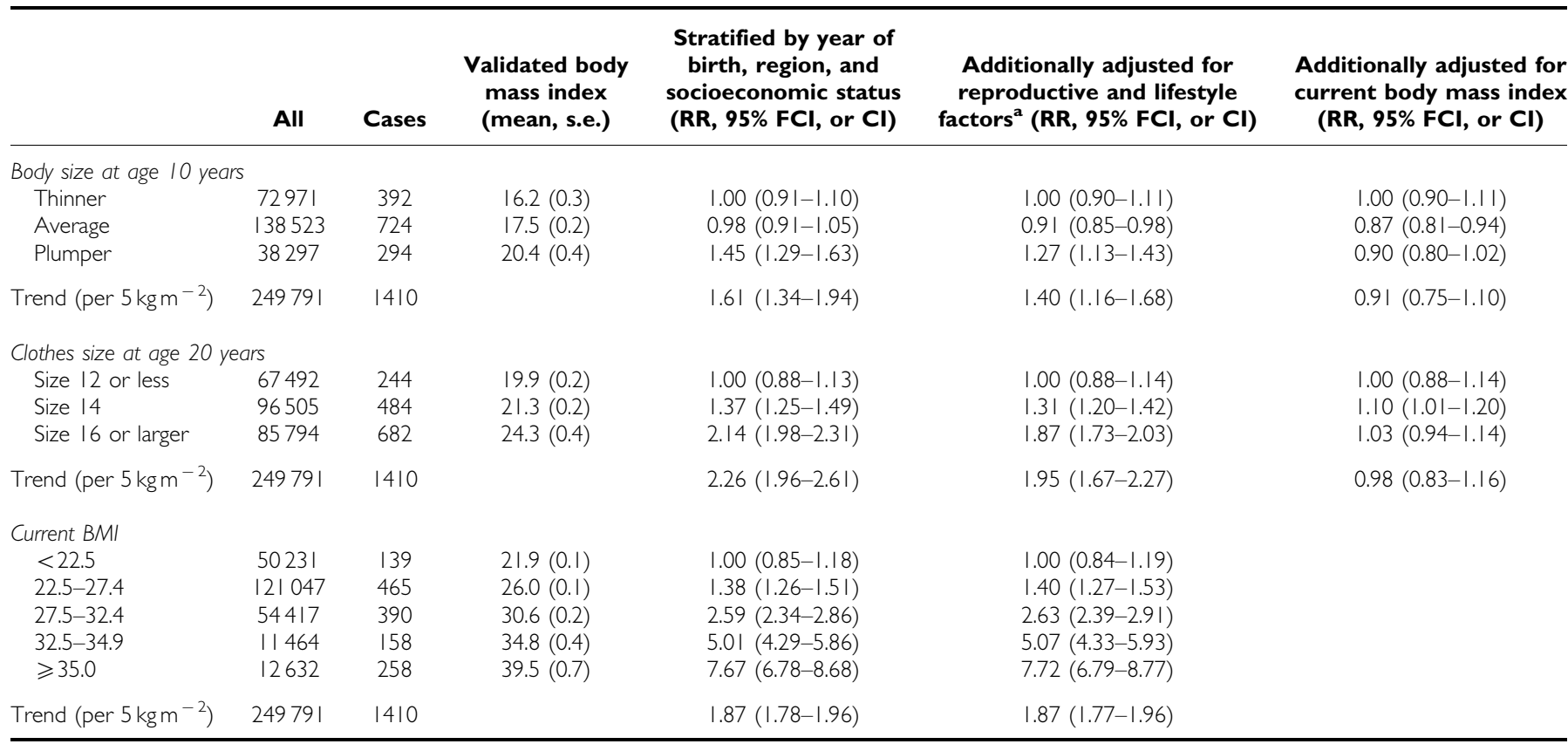

Abbreviations: $\mathrm{BMI}=$ body mass index; $\mathrm{Cl}=$ confidence interval; $\mathrm{FCl}=$ floated confidence interval; $\mathrm{RR}=$ relative risk. ${ }^{2}$ Adult height, age at menarche, parity, age at menopause, use of hormone contraceptives, alcohol consumption, smoking, and strenuous exercise.

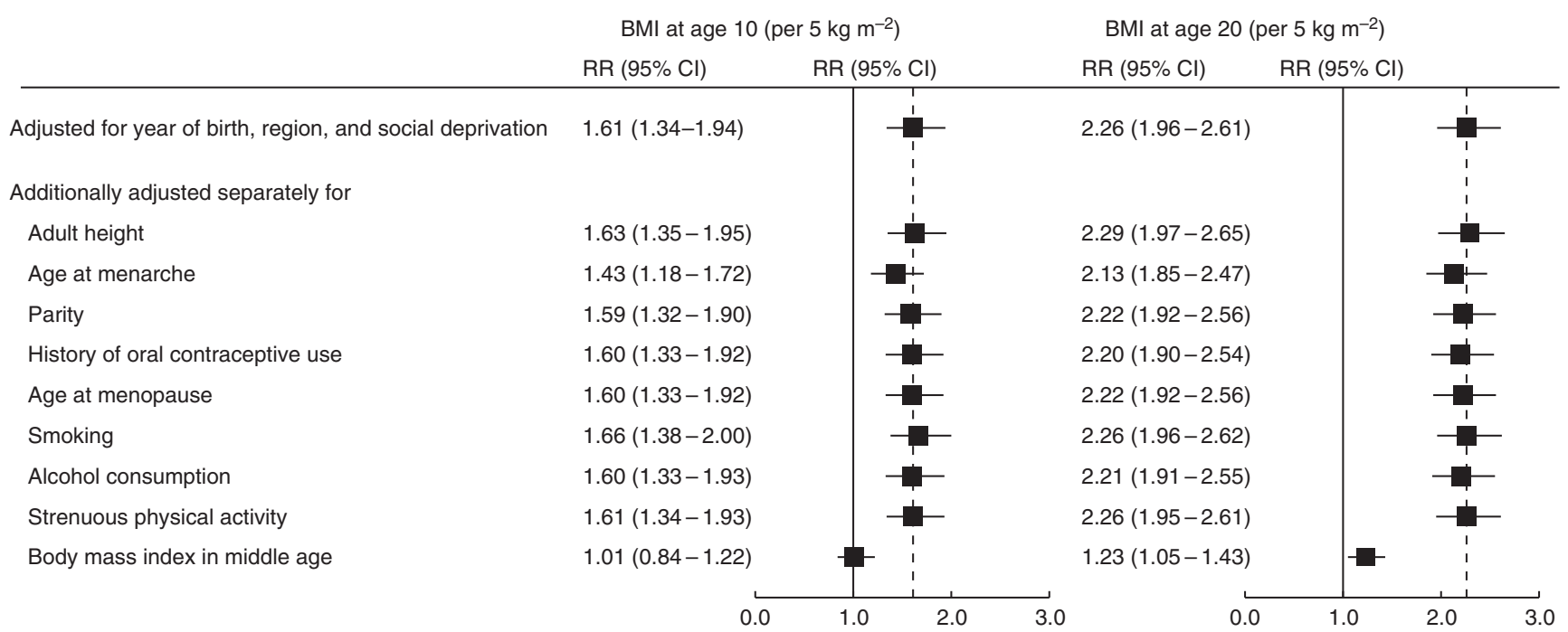

Figure 2 Relative risks (RRs) and 95\% confidence intervals (Cls) of endometrial cancer per $5 \mathrm{~kg} \mathrm{~m}^{-2}$ increase in body mass index (BMI) at age 10 and 20 years: effect of adjustment by various factors.

current BMI there was no evidence of excess risk (compared with women with clothes size 12 or less, $\mathrm{RR}=1.10,95 \% \mathrm{CI}: 0.94-1.29$, for size 14 , and $R R=1.03,95 \%$ CI: $0.88-1.22$, for size 16 or larger). This corresponded to a RR of 2.26 per $5 \mathrm{~kg} \mathrm{~m}^{-2}$ increase in BMI at age 20 years (95\% CI: 1.96-1.21) with minimal adjustment, which was attenuated after additional multivariable adjustment for variables other than current BMI $\left(\mathrm{RR}=1.95\right.$ per $5 \mathrm{~kg} \mathrm{~m}^{-2}, 95 \%$ CI: 1.67-2.27), and disappeared after further adjustment for current BMI $\left(\mathrm{RR}=0.98\right.$ per $\left.5 \mathrm{~kg} \mathrm{~m}^{-2}, 95 \% \mathrm{CI}: 0.83-1.16\right)$.

The individual effects of adjustment for each of the reproductive and lifestyle factors and current BMI, in addition to stratification by year of birth, region, and socioeconomic status, were also explored (Figure 2). Each of these factors had little effect individually on the RRs of postmenopausal endometrial cancer, except for current BMI, adjustment for which reduced the RRs to
1.01 per $5 \mathrm{~kg} \mathrm{~m}^{-2}$ (95\% CI: $\left.0.84-1.22\right)$ for body size at age 10 years and 1.23 per $5 \mathrm{~kg} \mathrm{~m}^{-2}(1.05-1.43)$ for body size at age 20 years.

We also investigated the risk of endometrial cancer by body size at age 10 or 20 years within subgroups of women by current BMI (Figure 3). The adjusted RRs of endometrial cancer were similar within each subgroup of current BMI, regardless of body size at 10 years, or clothes size at age 20 years, resulting in no significant interactions between current BMI and early life body size at either age (for interaction, $P=0.18$ for age 10 years and $P=0.93$ for age 20 years).

To assess any further potential for effect modification by other factors, the RR per $5 \mathrm{~kg} \mathrm{~m}^{-2} \mathrm{BMI}$ at age 10 or 20 years, adjusted for all covariates including current BMI, was compared across subgroups of various individual characteristics, including year of birth, socioeconomic status, adult height, age at menarche, parity, 

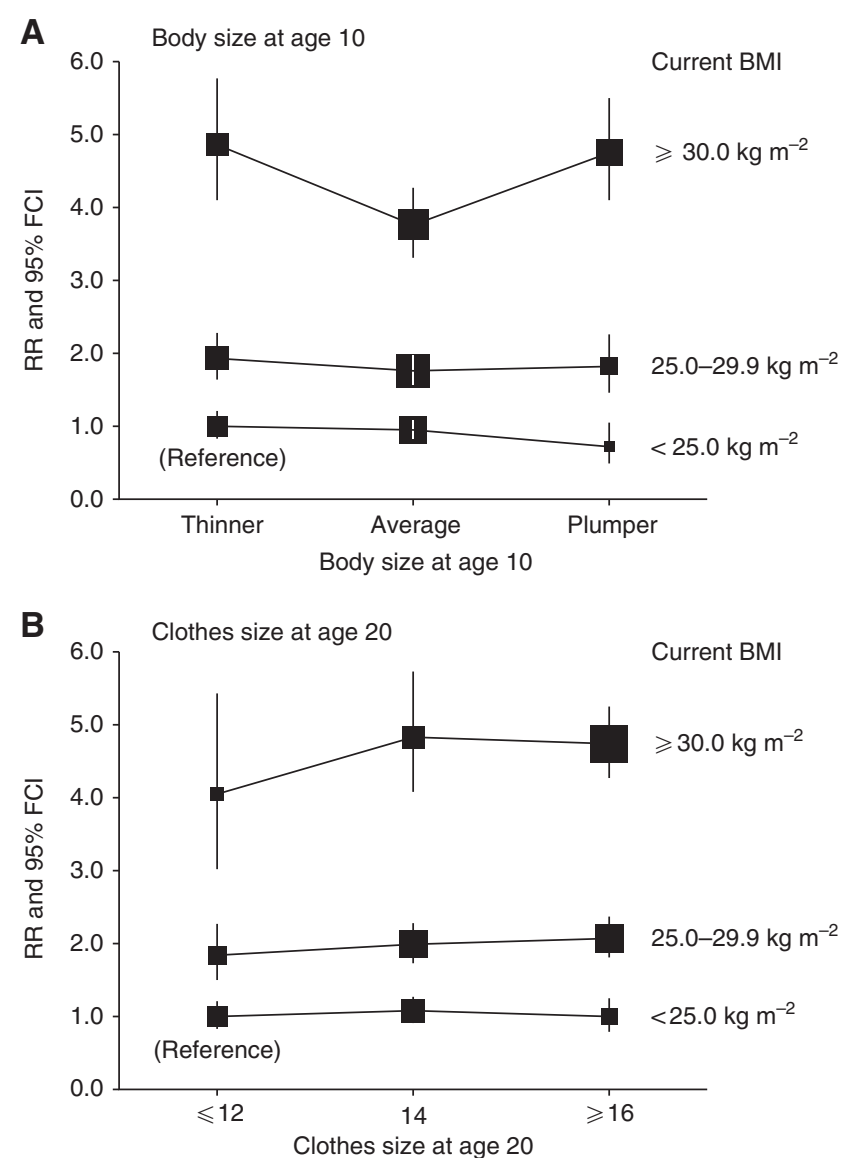

Figure 3 Relative risks (RRs) and floated confidence intervals ( $\mathrm{FCls}$ ) of endometrial cancer in relation to early life body size at age 10 years $(\mathbf{A})$ and 20 years $(\mathbf{B})$, by current body mass index (BMI). Relative risks are adjusted for age, region, socioeconomic status, adult height, age at menarche, parity, age at menopause, use of hormone contraceptives, alcohol consumption, smoking, and strenuous physical activity.

history of use of hormonal contraceptives, age at menopause, alcohol consumption, exercise, and smoking status (Figure 4). Weak evidence of heterogeneity was found in trends according to body size at age 10 years by smoking status $(P=0.02)$, and according to body size at age 20 years by year of birth $(P=0.04)$. However, neither of these $P$-values was significant after adjustment for multiple testing. No significant heterogeneity was observed by subgroups of any other characteristics for the trend in risk of endometrial cancer per $5 \mathrm{~kg} \mathrm{~m}^{-2}$ BMI at age 10 or 20 years.

\section{DISCUSSION}

The incidence of endometrial cancer in Great Britain has risen by more than $40 \%$ since the early 1990s (Office for National Statistics, 2002, 2012), which may have been driven, in part, by substantial increases in obesity over the same period (The NHS Information Centre, 2010). The association between adult body size and endometrial cancer is well established in the epidemiological literature (Reeves et al, 2007; Renehan et al, 2008; Crosbie et al, 2010), and is thought to be because of the production of sex hormones by adipose tissue, which may be particularly relevant after menopause (Calle and Kaaks, 2004). This is consistent with a meta-analysis that demonstrated a stronger association between BMI and endometrial cancer risk among postmenopausal women compared with premenopausal women, and among never users of hormone therapy for menopause compared with ever users
(Crosbie et al, 2010). In order to avoid the possibility that use of hormone therapy for menopause might mask the associations of any of the body size variables with endometrial cancer risk, our analyses were restricted to postmenopausal women who were never users of menopausal hormone therapies at baseline, and our estimate of the association between endometrial cancer risk and current BMI measured and validated in middle age $(\mathrm{RR}=1.87$ per $5 \mathrm{~kg} \mathrm{~m}^{-2}, 95 \%$ CI: $\left.1.77-1.96\right)$ is consistent with that of a recent meta-analysis and with previous studies among women who had never used menopausal hormone therapies (Chang et al, 2007; Friedenreich et al, 2007; McCullough et al, 2008; Crosbie et al, 2010).

Compared with that for adult body size, evidence regarding the effects of early-life body size on risk of endometrial cancer is sparse. Several cohort and case-control studies have found associations between body size in early adulthood and endometrial cancer risk (Blitzer et al, 1976; Le Marchand et al, 1991; Olson et al, 1995; Schouten et al, 2004; Trentham-Dietz et al, 2006; Xu et al, 2006; Park et al, 2009; Thomas et al, 2009), but whether this association is independent from adult body size has remained unclear. In the NIH-AARP Diet and Health Study Cohort (Chang et al, 2007), larger body size in early adulthood was associated with a greater risk of endometrial cancer among women in their fifties and sixties, but this association was not significant after adjustment for various factors including body size in middle age. Although several studies have looked at the association of endometrial cancer with body size in early life, to our knowledge none has looked at the association with childhood body size.

We observed modest correlations between body size in childhood or early adulthood and adiposity in later life. However, adult BMI is strongly associated with endometrial cancer risk, so even modest correlations between current BMI and body size in early life could produce substantial associations of higher risk of endometrial cancer with larger body size in early life. We found, however, that associations between risk of postmenopausal endometrial cancer and larger body size in both childhood and early adulthood disappeared after adjustment for current BMI. In addition, there were no significant differences in endometrial cancer risk by body size at age 10 or 20 years within fixed levels of current BMI. Together, these findings suggest that the association of larger body size in childhood and early adulthood with higher risk of endometrial cancer may be mediated largely through current BMI.

We cannot exclude the possibility of a small association of endometrial cancer risk with body size in early life, independent of current BMI. The strength of the association between early-life body size and risk of postmenopausal endometrial cancer might be underestimated after adjustment for current BMI, if the latter was highly correlated with early life body size and was much more reliably reported than body size in early years. However, data from the 1957 UK birth cohort suggest that although BMI in childhood is correlated with BMI in adulthood, these correlations are not strong (correlation $r=0.32$ for BMI of women at ages 7 and 33 years) (Lake et al, 1997). We cannot exclude residual confounding due to imperfect measurement of other covariates, or by unknown factors. Although we have excluded women who had a history of hysterectomy at baseline, a small proportion of women may have had a hysterectomy during follow-up. This could result in small biases to estimates of RRs as women with higher BMI may have a higher hysterectomy rate (Cooper et al, 2005).

In addition to its large size, a strength of this study is the use of measures of body size in early life and in middle age, which have been calibrated to prospectively collected BMI in a subset of study participants (Armstrong et al, 2011; Cairns et al, 2011). The comparison of these self-reports with prospectively collected BMI data suggests that self-reported categories of relative body size at age 10 and clothes size at age 20 years are representative of different levels of body fatness at those ages. However, extremely 


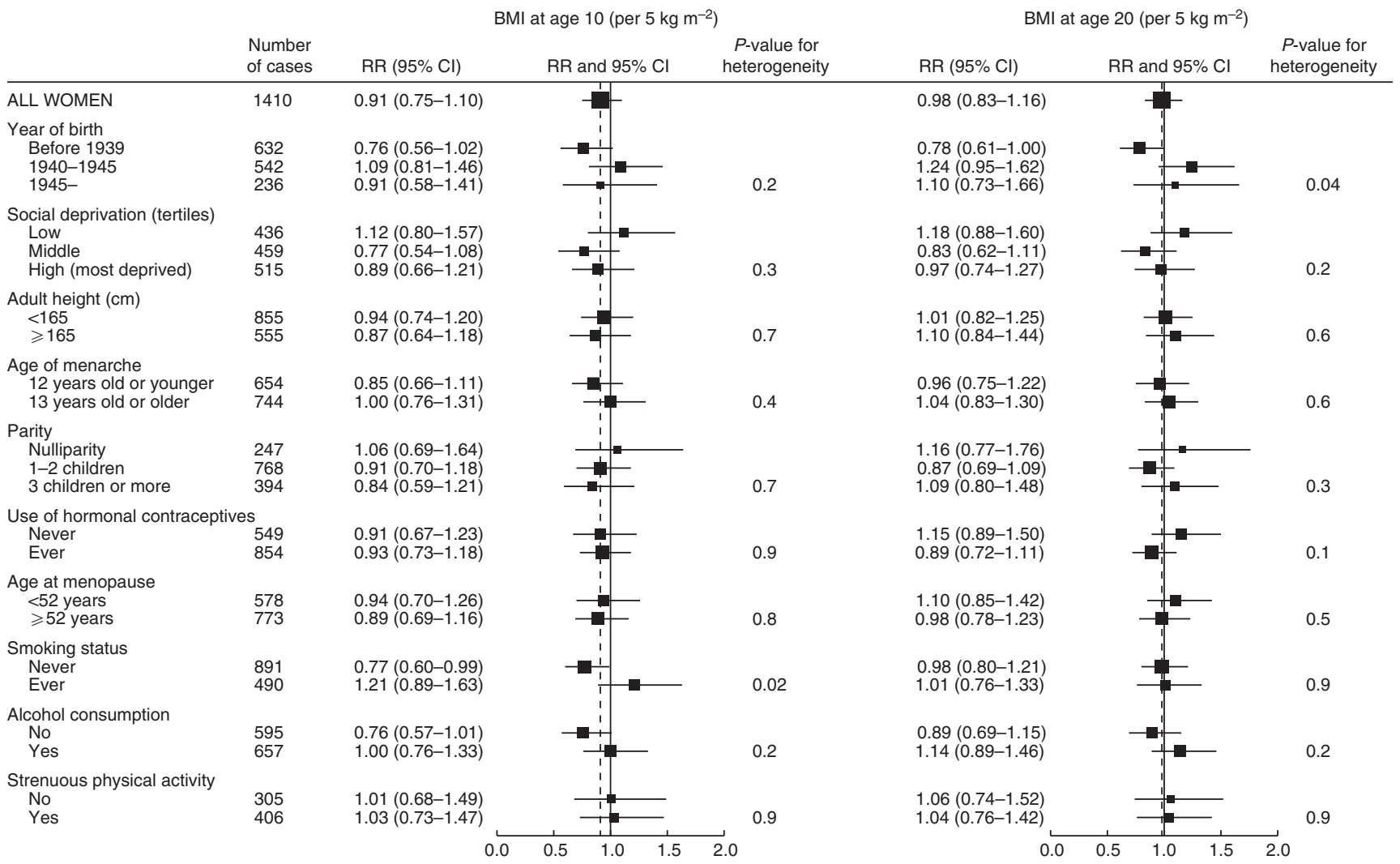

Figure 4 Relative risks (RRs) and 95\% confidence intervals (Cls) of endometrial cancer per $5 \mathrm{~kg} \mathrm{~m}^{-2}$ increase in body mass index (BMI) at age 10 and 20 years, by various characteristics.

large or small body sizes in early life might show different patterns of association with endometrial cancer risk, and affect the representativeness of linear trend estimates. In addition, clothes size at age 20 was validated only against BMI reported, but not measured, at age 20 , which would still be subject to reporting error that, while not likely to be extreme, could not be quantified. Compared with other body size indicators, clothes size at age 20 has a relatively strong and positive association with attained adult height in our analysis, and may be representative both of height and of adiposity at that age. Height is an independent risk factor for endometrial cancer (Green et al, 2011), and despite adjustment for height there may be some small residual confounding between height and clothes size at age 20 years. Nevertheless, our results for age 20 were consistent with previous reports in demonstrating the apparent association between other types of body size measures in early adulthood and endometrial cancer before adjustment for BMI in later life (Blitzer et al, 1976; Le Marchand et al, 1991; Olson et al, 1995; Schouten et al, 2004; Trentham-Dietz et al, 2006; Xu et al, 2006; Park et al, 2009; Thomas et al, 2009).

\section{REFERENCES}

Allen NE, Beral V, Casabonne D, Kan SW, Reeves GK, Brown A, Green J (2009) Moderate alcohol intake and cancer incidence in women. J Natl Cancer Inst 101: 296-305

Allen NE, Key TJ, Dossus L, Rinaldi S, Cust A, Lukanova A, Peeters PH, Onland-Moret NC, Lahmann PH, Berrino F, Panico S, Larranaga N, Pera G, Tormo MJ, Sanchez MJ, Quiros JR, Ardanaz E, Tjonneland A, Olsen A, Chang-Claude J, Linseisen J, Schulz M, Boeing H, Lundin E, Palli D, Overvad K, Clavel-Chapelon F, Boutron-Ruault MC, Bingham S, Khaw KT, Bueno-De-Mesquita HB, Trichopoulou A, Trichopoulos D, Naska A,
In this study, we used validated measures of body size at ages 10 and 20 years, and current BMI, to assess whether apparent associations between early life body size and postmenopausal endometrial cancer risk might be mediated or modified by BMI in later adulthood among women who had never used hormone therapy for menopause. Our results suggest that the association between larger body size in early life and increased risk of postmenopausal endometrial cancer are mediated mainly through the correlation between greater body size in early life and greater adiposity in later life.

\section{ACKNOWLEDGEMENTS}

We thank all of the women who participated in the Million Women Study. We would also like to thank Mr Adrian Goodill for his assistance in the preparation of the figures. The Million Women Study is supported by Cancer Research UK, the UK Medical Research Council, and the UK National Health Service Breast Screening Programme.

Tumino R, Riboli E, Kaaks R (2008) Endogenous sex hormones and endometrial cancer risk in women in the European Prospective Investigation into Cancer and Nutrition (EPIC). Endocr-Relat Cancer 15: 485-497

Armstrong MEG, Spencer EA, Cairns BJ, Banks E, Pirie K, Green J, Wright FL, Reeves GK, Beral V for the Million Women Study C (2011) Body mass index and physical activity in relation to the incidence of hip fracture in postmenopausal women. J Bone Miner Res 26(6): $1330-1338$ 
Baer HJ, Tworoger SS, Hankinson SE, Willett WC (2010) Body fatness at young ages and risk of breast cancer throughout life. Am J Epidemiol 171: 1183-1194

Blitzer PH, Blitzer EC, Rimm AA (1976) Association between teen-age obesity and cancer in 56,111 women - all cancers and endometrial carcinoma. Prev Med 5: 20-31

Cairns BJ, Liu B, Clennell S, Cooper R, Reeves GK, Beral V, Kuh D (2011) Lifetime body size and reproductive factors: comparisons of data recorded prospectively with self reports in middle age. BMC Med Res Methodol 11: 13

Calle EE, Kaaks R (2004) Overweight, obesity and cancer: Epidemiological evidence and proposed mechanisms. Nat Rev Cancer 4: 579-591

Chang SC, Lacey JV, Brinton LA, Hartge P, Adams K, Mouw T, Carroll L, Hollenbeck A, Schatzkin A, Leitzmann MF (2007) Lifetime weight history and endometrial cancer risk by type of menopausal hormone use in the NIH-AARP diet and health study. Cancer Epidemiol Biomarkers Prev 16: 723-730

Cooper R, Lawlor DA, Hardy R, Ebrahim S, Leon DA, Wadsworth MEJ, Kuh D (2005) Socio-economic position across the life course and hysterectomy in three British cohorts: a cross-cohort comparative study. BJOG 112: 1126-1133

Crosbie EJ, Zwahlen M, Kitchener HC, Egger M, Renehan AG (2010) Body mass index, hormone replacement therapy, and endometrial cancer risk: a meta-analysis. Cancer Epidemiol Biomarkers Prev 19: 3119-3130

Easton DF, Peto J, Babiker A (1991) Floating absolute risk - an alternative to relative risk in survival and case-control analysis avoiding an arbitrary reference group. Stat Med 10: 1025-1035

Friedenreich C, Cust A, Lahmann PH, Steindorf K, Boutron-Ruault MC, Clavel-Chapelon F, Mesrine S, Linseisen J, Rohrmann S, Boeing H, Pischon T, Tjonneland A, Halkjaer J, Overvad K, Mendez M, Redondo ML, Garcia CM, Larranaga N, Tormo MJ, Gurrea AB, Bingham S, Khaw KT, Allen N, Key T, Trichopoulou A, Vasilopoulou E, Trichopoulos D, Pala V, Palli D, Tumino R, Mattiello A, Vineis P, Bueno-de-Mesquita HB, Peeters PHM, Berglund G, Manjer J, Lundin E, Lukanova A, Slimani N, Jenab M, Kaaks R, Riboli E (2007) Anthropometric factors and risk of endometrial cancer: the European prospective investigation into cancer and nutrition. Cancer Causes Control 18: 399-413

Green J, Cairns BJ, Casabonne D, Wright FL, Reeves G, Beral V (2011) Height and cancer incidence in the Million Women Study: prospective cohort, and meta-analysis of prospective studies of height and total cancer risk. Lancet Oncol 12: 785-794

Holm S (1979) A simple sequentially rejective multiple test procedure. Scand J Stat 6: 65-70

Lake JK, Power C, Cole TJ (1997) Child to adult body mass index in the 1958 British birth cohort: associations with parental obesity. Arch Dis Child 77: 376-381
Le Marchand L, Kolonel LN, Earle ME, Mi M-P (1988) Body size at different periods of life and breast cancer risk. Am J Epidemiol 128: 137-152

Le Marchand L, Wilkens LR, Mi MP (1991) Early-age body size, adult weight gain and endometrial cancer risk. Int J Cancer 48: 807-811

McCullough ML, Patel AV, Patel R, Rodriguez C, Feigelson HS, Bandera EV, Gansler T, Thun MJ, Calle EE (2008) Body mass and endometrial cancer risk by hormone replacement therapy and cancer subtype. Cancer Epidemiol Biomarkers Prev 17: 73-79

Million Women Study Collaborators (2003) Breast cancer and hormonereplacement therapy in the Million Women Study. Lancet 362: 419-427

Office for National Statistics (2002) Cancer Statistics Registrations, England (Series MB1) - No. 29, 1998 data tables. Website http://www.ons.gov.uk/. Accessed on 03 April 2012

Office for National Statistics (2012) Cancer incidence and mortality in the UK, 2007-2009. Website http://www.ons.gov.uk/. Accessed on 03 April 2012

Olson SH, Trevisan M, Marshall JR, Graham S, Zielezny M, Vena JE, Hellmann R, Freudenheim JL (1995) Body-mass index, weight-gain, and risk of endometrial cancer. Nutr Cancer 23: 141-149

Park SL, Goodman MT, Zhang ZF, Kolonel LN, Henderson BE, Setiawan VW (2009) Body size, adult BMI gain and endometrial cancer risk: the multiethnic cohort. Int J Cancer 126: 490-499

Plummer M (2004) Improved estimates of floating absolute risk. Stat Med 23: $93-104$

Reeves GK, Pirie K, Beral V, Green J, Spencer E, Bull D (2007) Cancer incidence and mortality in relation to body mass index in the Million Women Study: cohort study. Br Med J 335: 1134-1139

Renehan AG, Tyson M, Egger M, Heller RF, Zwahlen M (2008) Body-mass index and incidence of cancer: a systematic review and meta-analysis of prospective observational studies. Lancet 371: 569-578

Schouten LJ, Goldbohm RA, van den Brandt PA (2004) Anthropometry, physical activity, and endometrial cancer risk: results from the Netherlands cohort study. J Natl Cancer Inst 96: 1635-1638

The NHS Information Centre (2010) Statistics on Obesity, Physical Activity and Diet: England 2010. The NHS Information Centre, Lifestyle Statistics. URL: http://www.ic.nhs.uk/pubs/opad10

Thomas CC, Wingo PA, Dolan MS, Lee NC, Richardson LC (2009) Endometrial cancer risk among younger, overweight women. Obstet Gynecol 114: 22-27

Townsend P, Phillimore P, Beattie A (1988) Health and Deprivation: Inequality and the North. Croon Helm: London

Trentham-Dietz A, Nichols HB, Hampton JM, Newcomb PA (2006) Weight change and risk of endometrial cancer. Int J Epidemiol 35: 151-158

Xu WH, Xiang YB, Zheng W, Zhang XL, Ruan ZX, Cheng JR, Gao YT, Shu $\mathrm{XO}$ (2006) Weight history and risk of endometrial cancer among Chinese women. Int J Epidemiol 35: 159-166

This work is published under the standard license to publish agreement. After 12 months the work will become freely available and the license terms will switch to a Creative Commons Attribution-NonCommercial-Share Alike 3.0 Unported License. 